\title{
ASPECTOS CONTEMPORÂNEOS DA CENTRALIDADE URBANA: O CASO DE VITÓRIA
}

Heldo Siqueira da Silva ${ }^{1}$

RESUMO: O artigo visa identificar alguns fenômenos teóricos da centralidade urbana no município de Vitória, capital do Espírito Santo, a partir de seus bairros. Para essa atividade busca-se criar duas perspectivas diferentes. A primeira refere-se às mudanças da centralidade urbana ao longo do tempo, para o qual são estudadas a distribuição dos estabelecimentos varejistas e registros de pessoas jurídicas entre 1970 e 2012. O segundo corte diz respeito à distribuição populacional e da estrutura econômica, para o qual são estudadas a distribuição dos equipamentos urbanos e dos estabelecimentos comerciais.

Palavras-Chave: Centralidade urbana. Ocupação urbana. Desigualdades socioespaciais.

\footnotetext{
${ }^{1}$ Professor da Universidade Candido Mendes e analista de suporte em desenvolvimento organizacional do Instituto de Defesa Agropecuária e Florestal do Espirito Santo. Mestre em Economia pela Universidade Federal do Espírito Santo. E-mail: heldojr@hotmail.com
} 


\section{INTRODUÇÃO}

Um dos elementos fundamentais da sociedade capitalista é sua organização a partir dos centros urbanos. A criação de mercado consumidor vinculado ao abrigo para a população industrial permite a reprodução do capital. Em relação à instalação e expansão dos centros urbanos, estudos como o de Milton Santos (2008) apontam para o fato de que a ocupação em termos espaciais das cidades capitalistas, mais precisamente dos países subdesenvolvidos, acontece de maneira desigual. Trata-se, portanto, de um elemento a ser observado ao se estudar o fenômeno da expansão das capitais urbanas. Outros autores, estudando a evolução contemporânea dessas capitais observam as modificações que a centralidade apresenta, como nos estudos de Corrêa, Pitaudi e Vasconcelos (2013).

Para observar alguns desses elementos no caso específico de Vitória, organizouse $o$ trabalho em seis partes. Além desta introdução, apresenta-se uma reflexão teórica sobre os principais aspectos da centralidade urbana. Posteriormente é feita uma análise da evolução dos espaços com maior incidência de atividade econômica entre 1970 e 2012, como uma reflexão sobre a evolução das localidades mais importantes. A seção seguinte trata da distribuição dos equipamentos urbanos para identificar aspectos de segregação espacial ou de indivíduos observados em Vitória. As considerações finais são apresentadas em seguida e, por fim, são elencados os anexos do trabalho.

\section{QUESTÕES SOBRE A OCUPAÇÃO DO ESPAÇO URBANO}

Estudando o padrão das atividades agrícolas nas cidades da Alemanha préindustrial, Johann Heirich Von Thünen (1783-1850) identificou um padrão de otimização, segundo o qual a localização de um empreendimento diz respeito a minimização de custos entre o transporte de uma mercadoria e a renda da terra paga para produzi-la. Já a distribuição das atividades econômicas em relação ao espaço é o resultado do equilíbrio competitivo do mercado de terras em relação a um centro consumidor. O resultado desse arranjo determina o centro consumidor como o local em torno do qual se organizam as atividades rurais. Nos trabalhos de Isard e Alonso, esse conceito de centralidade é substituído pela ideia de Distrito Central de Negócios (em inglês Central Business District - CBD), que também funciona como um centro de 
empregos. Por essa perspectiva, "o conceito básico da economia urbana é o mercado de terras, que serve para alocar agentes e atividades econômicas no espaço." (TISSE, 2011, p. 16).

Essa avaliação parece fértil em termos de entender a dinâmica pontual do crescimento das cidades a partir de atividades econômicas específicas, mas não permite entender a integração entre um centro urbano específico juntamente com suas localidades periféricas e o restante da economia. As preocupações de David Harvey (2005) apontam para esse sentido. Para ele, o progresso da acumulação capitalista está baseada em três pressupostos:

1) Existência de excedente de mão-de-obra, isto é, um exército de reserva industrial, que pode alimentar a expansão da produção. Portanto, devem existir mecanismos para aumento da oferta de força de trabalho, mediante, por exemplo, o estímulo ao crescimento populacional, a geração de correntes migratórias, a atração de 'elementos latentes' - força de trabalho emprega em situações não-capitalistas; mulheres, crianças etc. - para o trabalho, ou a criação de desemprego pelo uso de inovações que poupam trabalho.

2) A existência no mercado de quantidades necessárias (ou oportunidades de obtenção) de meios de produção - máquinas, matérias-primas, infraestrutura física e assim por diante -, que possibilitam a expansão da produção conforme o capital reinvestido.

3) A existência de mercado para absorver as quantidades crescentes de mercadorias produzidas. Se não puderem ser encontradas necessidades para os bens, ou se não existir demanda efetiva (a necessidade retraída pela incapacidade de pagamento) então desaparecerão as condições para a acumulação capitalista (HARVEY, 2005, p. 45)

As condições descritas indicam que a acumulação capitalista necessita de centros urbanos a partir dos quais há, ao mesmo tempo, a oferta de mão de obra abundante, mercados de meios de produção e de bens de consumo. $O$ autor ainda acrescenta que, em alguns momentos, as condições de organização da produção fazem com que, a preços de mercado, seu valor seja maior a disponibilidade de renda nacional disponível para adquiri-la. Ou seja, a própria forma de organização produtiva limita cria limites para sua expansão. Nos momentos em que esse fenômeno acontece, há "A expansão geográfica para novas regiões, incrementando o comércio exterior, exportando capital e, em geral, expandindo-se rumo à criação do que Marx denominou 'o mercado mundial'" (HARVEY, 2005, p. 48) 
Interpretando a questão urbana sob uma lógica parecida, Corrêa (1989) argumenta que a lógica de desigualdade das sociedades organizadas a partir do modo de produção capitalista também se manifesta no espaço. Para o autor, é possível identificar dois tipos de fragmentação no espaço urbano. A primeira diz respeito à dicotomia entre a produção e a moradia. A outra oposição é em relação aos bairros ricos e pobres. A interação entre essas questões determinaria a ocupação das terras em uma determinada cidade.

O exercício intelectual de organizar os três aspectos da lógica urbana: i) sua vinculação à expansão capitalista; ii) a dicotomia entre as áreas de produção e moradia; e iii) a divisão entre os bairros ricos é pobres é apresentado no trabalho de Milton Santos (2008), com a formulação de sua teoria sobre os circuitos superior e inferior em relação à ocupação urbana.

Por sua lógica, o circuito superior, a economia formalizada, tem a tarefa de ligar a economia regional com o mercado mundial, denominado circuito moderno extraregional. As atividades de produção e comercialização voltadas para o mercado externo teriam a interação com as atividades regionais de transporte, ramo atacadista, o comércio local moderno e o ramo de serviços formalizados. Caberia a essas atividades locais a comunicação com o circuito inferior da economia, de fabricação não capitalista e comércio não moderno.

Quanto à questão espacial, há a indicação de que as atividades industriais voltadas para a exportação, mais especificamente a exploração de recursos naturais e commoditties agropecuárias nos países subdesenvolvidos, situam-se próximas as jazidas ou do complexo produtivo agropecuário. As regiões centrais das cidades seriam ocupadas pelas atividades regionais do circuito superior e atenderiam alguns dos bairros ricos nos seus arredores. A indústria urbana tenderia a se localizar nos locais mais afastados dos centros urbanos, onde o preço das terras é menos valorizado, diminuindo o custo da produção. Em volta desses empreendimentos industriais cresceriam os bairros pobres que abrigariam sua mão-de-obra. Esses bairros pobres gerariam centralidades menores atendidas pelo circuito inferior da economia regional. 
No que tange aos aspectos dos padrões espaciais Corrêa, Pitaudi e Vasconcelos (2013) argumentam que há diferenças entre diferenciação socioespacial e desigualdade socioespacial. A primeira perspectiva está ligada à lógica de diferenciação de espaço em termos da observação visual enquanto a segunda está ligada a ideia de exclusão social, segundo a qual "os excluídos seriam pessoas rejeitadas fisicamente (racismo), geograficamente (gueto) e materialmente (pobreza) [...]" (2013, p. 22). No caso da diferenciação socioespacial, a forma de construção ou de organização do espaço permite identificar visualmente a diferenciação. Ao contrário, alguns casos de desigualdade socioespacial são imperceptíveis sem a análise social. Para os autores:

[...] os melhores exemplos de diferenças socioespaciais se encontram nas formas das antigas cidades coloniais africanas, entre os bairros europeus e indígenas. Neste caso, as formas sociais são diferentes das estruturas espaciais. Os 'guetos' negros norte americanos, por outro lado, são invisíveis aos aviões, na medida em que as formas espaciais não são diferenciadas. (CORRÊA, PITAUDI e VASCONCELOS, 2013, p. 18)

No caso particular da análise em relação ao aparecimento de diferenças geoespaciais na ocupação urbana, os autores identificam três processos com características diferentes. Em relação à i) proximidade de áreas diferentes, há a justaposição, que aparece quando há uma proximidade espacial com distância social sem que haja barreira entre as comunidades, e separação, quando a mesma proximidade espacial é dividida por uma barreira física; ii) A dispersão ocorre quando os subúrbios dos bairros afastados crescem de maneira a gerar novos centros menores, afastados do centro original; e iii) quanto à divisão do espaço em de atividades econômicas diversas, há a divisão em partes, representada por identificação de distritos específicos para atividades econômicas ou moradia e a fragmentação, que ocorre quando há a disfuncionalidade da lógica de centralidade, gerando espaços locais ocupados por atividades desconexas, mesmo com populações socialmente homogêneas.

Ainda sobre a questão dos padrões de ocupação urbana, os primeiros modelos apresentavam a ocupação dos centros urbanos, cujas terras seriam mais valorizadas, pelas classes mais abastadas, com a ocupação por famílias cada vez mais pobres à medida em que afastava-se do centro. Essa perspectiva foi revista posteriormente, 
quando identificou-se que em alguns centros urbanos, os terrenos das áreas centrais perdiam o valor de mercado, passando a ser ocupados pelas classes de poder aquisitivo menor, que ainda encontravam nessas regiões o fácil acesso ao trabalho. Como uma síntese dessas abordagens o modelo de Homer Hoyt (1895-1984) que aborda questões relativas à tendência de áreas residenciais em situar-se ao longo das principais rodovias, à substituição residencial que ocorre pela variação dos preços dos imóveis, à predisposição das moradias de baixa renda aos locais de trabalho e à tendência de autossegregação dos bairros de alto padrão a partir da expansão imobiliária (CARLOS e RICCI, 2015).

\section{A CENTRALIDADE NO MUNICÍPIO DE VITÓRIA EM RELAÇÃO AO TEMPO}

Elevada à categoria de cidade em 1823, a história da construção da centralidade de Vitória em relação ao Espírito Santo passa por diversas disputas políticas. A expansão do café na região sul do Estado, centralizada em Cachoeiro do Itapemirim durante o transcorrer do século XIX é seguida pela decisão de Muniz Freire, após a proclamação da República, de construir uma centralidade que polarizasse econômica e politicamente o Estado. Em suas palavras:

O argumento mais imediato em favor da necessidade dos grandes centros é fornecido pela lição de todos os tempos e de todos os povos. Não há país no mundo, de importância política ou comercial, que não tenha as suas grandes praças, e quanto mais notável são estas mais elevada é a categoria da nação; as primeiras nações do globo são a França, a Inglaterra, os Estados Unidos e a Alemanha, que possuem cidades como Paris, Londres, Nova York, além de tantas outras que figuram em primeira linha após estas. (MUNIZ FREIRE, 1896, apud CAMPOS JR., 1996, p. 148)

Essa iniciativa foi sucedida pela construção de diversas estradas de ferro que passavam a ligar as demais regiões do Estado com a capital, da estruturação do porto que serviria para escoamento, ao invés do Rio de Janeiro, e da construção do novo arrabalde que abrigaria os moradores da cidade. Ao longo das primeiras décadas do século XX as obras de ligação do interior com a capital e de melhoramento da cidade foram sendo concluídas. Quanto ao porto, no final da década de $1920,76,42 \%$ da produção de café do Estado era feita pelo porto de Vitória.

As décadas que se seguiram, marcam a relativa decadência da agricultura cafeeira capixaba e da emergência da industrialização no Brasil. O porto de Vitória, que 
antes voltava-se ao escoamento da produção da commoditty, passa a se adequar aos empreendimentos industriais de Minas Gerais. Segundo Buffon:

Os produtos manufaturados importados pelo porto passam a estar voltados preponderantemente para suprir às necessidades da "industrialização mineira" e, no total exportado, passam a predominar as exportações de minério de ferro. Ou seja, apesar de estar localizado no Espírito Santo, no período em análise, o porto de Vitória foi mais mineiro do que capixaba. Este é o resultado da forma específica com a qual o Espírito Santo integrou-se ao conjunto da economia brasileira: manteve (sobretudo o interior do Estado) a sua histórica ligação com o Distrito Federal, agora na condição de periferia nacional; e atuou (fundamentalmente a cidade de Vitória) como um ponto avançado da economia mineira junto ao litoral. (BUFFON, 1992, p. 250)

Para ele, a consolidação a centralidade de Vitória, além da modificação em relação ao escoamento da produção agrícola capixaba, é marcada tem outro marco: "Com o início da operação do novo terminal de cargas da CVRD em 1966 (o porto de Tubarão), encerra-se este período, que constitui a primeira fase de transição para um padrão urbano-industrial, que assumirá contornos definitivos em meados da década de setenta" (BUFFON, 1992, p. 321).

As mudanças na orientação da economia capixaba em termos gerais e dos produtos de escoamento nos terminais de Vitória especificamente, causaram alterações na estrutura da capital. Gonring (2011), estudando a redefinição funcional do Centro de Vitória nos últimos anos, percebeu que a gênese central da região foi a ligação com o restante do mundo através da ligação com transporte ferroviário e o escoamento do porto de Vitória. Essa posição permitiu ao município a centralidade em relação aos demais municípios do Estado e o posicionamento como mediador nas questões relativas à efetividade em termos de integração nacional. Entretanto, conforme houve a modificação da estrutura produtiva, o bairro deixou de ter os elementos adequados ao processo contínuo de valorização do capital. Para ele:

Na medida em que o polo industrial impulsionou o processo de urbanização e desenvolvimento da área continental, a ilha de Vitória começou a sua expansão territorial, partindo do Centro da Cidade principalmente em direção à região das praias, na sua porção norte, aumentando seu território por meio de aterros que foram substituindo os mangues e áreas alagadas da ilha (GONRING, 2011, p. 118).

Outro autor que estudou o fenômeno da descentralização em Vitória, Reis (2007) comparou o fenômeno da descentralização em Vitória em direção à Praia do Canto com 
a construção de outro subcentro urbano da Região Metropolitana da Grande Vitória (RMGV), Campo Grande, em Cariacica. As evidências apontaram para o fato de que o Bairro da capital apresentava todos os elementos, em termos estruturais, econômicos e urbanísticos para ser considerada uma área central (CBD). Ou seja, o autor encontrou elementos, entre o final da década de 1990 para meados da década de 2000, para considerar a região das praias mais próximas do continente como área central do município. A tabela 1 mostra a proporção de estabelecimentos varejistas nos anos de 1970, 1980, 1990 e 1999 e o número de pessoas jurídicas registradas como Microempresas (ME), Empresas de Pequeno Porte (EPP) e Demais na prefeitura em $2012^{i}$ e o Mapa I mostra a distribuição dos bairros e regiões administrativas de Vitória.

Tabela 1 - Estabelecimentos varejistas entre 1970 a 1999 e registros de pessoas jurídicas na Prefeitura em 2012 nas regiões administrativas de Vitória ${ }^{\text {ii }}$

\begin{tabular}{lrrrrr}
\hline \multicolumn{1}{c}{ Região administrativa } & \multicolumn{1}{c}{$\mathbf{1 9 7 0}$} & \multicolumn{1}{c}{$\mathbf{1 9 8 0}$} & \multicolumn{1}{c}{$\mathbf{1 9 9 0}$} & \multicolumn{1}{c}{$\mathbf{1 9 9 9}$} & \multicolumn{1}{c}{$\mathbf{2 0 1 2}$} \\
\hline \hline Região I - Centro & 937 & 2.223 & 3.517 & 4.278 & 4.417 \\
Região II - Santo Antônio & 114 & 237 & 414 & 590 & 1.279 \\
Região III - Jucutuquara & 204 & 606 & 1.340 & 1.973 & 2.903 \\
Região IV - Maruípe & 125 & 387 & 721 & 1.087 & 1.975 \\
Região V - Praia do Canto & 139 & 531 & 1.702 & 3.190 & 6.911 \\
Região VI - Goiabeiras & 61 & 398 & 1.522 & 2.878 & 6.454 \\
Região VII - São Pedro & 5 & 11 & 55 & 115 & 966 \\
\hline Total geral & $\mathbf{1 . 5 8 5}$ & $\mathbf{4 . 3 9 3}$ & $\mathbf{9 . 2 7 1}$ & $\mathbf{1 4 . 1 1 1}$ & $\mathbf{2 4 . 9 0 5}$ \\
\hline \multicolumn{1}{c}{ Região administrativa } & $\mathbf{1 9 7 0}$ & $\mathbf{1 9 8 0}$ & $\mathbf{1 9 9 0}$ & $\mathbf{1 9 9 9}$ & $\mathbf{2 0 1 2}$ \\
\hline Região I - Centro & $59,1 \%$ & $50,6 \%$ & $37,9 \%$ & $30,3 \%$ & $17,7 \%$ \\
Região II - Santo Antônio & $7,2 \%$ & $5,4 \%$ & $4,5 \%$ & $4,2 \%$ & $5,1 \%$ \\
Região III - Jucutuquara & $12,9 \%$ & $13,8 \%$ & $14,5 \%$ & $14,0 \%$ & $11,7 \%$ \\
Região IV - Maruípe & $7,9 \%$ & $8,8 \%$ & $7,8 \%$ & $7,7 \%$ & $7,9 \%$ \\
Região V - Praia do Canto & $8,8 \%$ & $12,1 \%$ & $18,4 \%$ & $22,6 \%$ & $27,7 \%$ \\
Região VI - Goiabeiras & $3,8 \%$ & $9,1 \%$ & $16,4 \%$ & $20,4 \%$ & $25,9 \%$ \\
Região VII - São Pedro & $0,3 \%$ & $0,3 \%$ & $0,6 \%$ & $0,8 \%$ & $3,9 \%$ \\
\hline Total geral & $\mathbf{1 0 0 , 0 \%}$ & $\mathbf{1 0 0 , 0 \%}$ & $\mathbf{1 0 0 , 0 \%}$ & $\mathbf{1 0 0 , 0 \%}$ & $\mathbf{1 0 0 , 0 \%}$ \\
\hline Fon & & &
\end{tabular}

Fonte: Reis (2007) e Prefeitura Municipal de Vitória (2016). 
Mapa 1 - Mapa dos bairros e regiões administrativas de Vitória

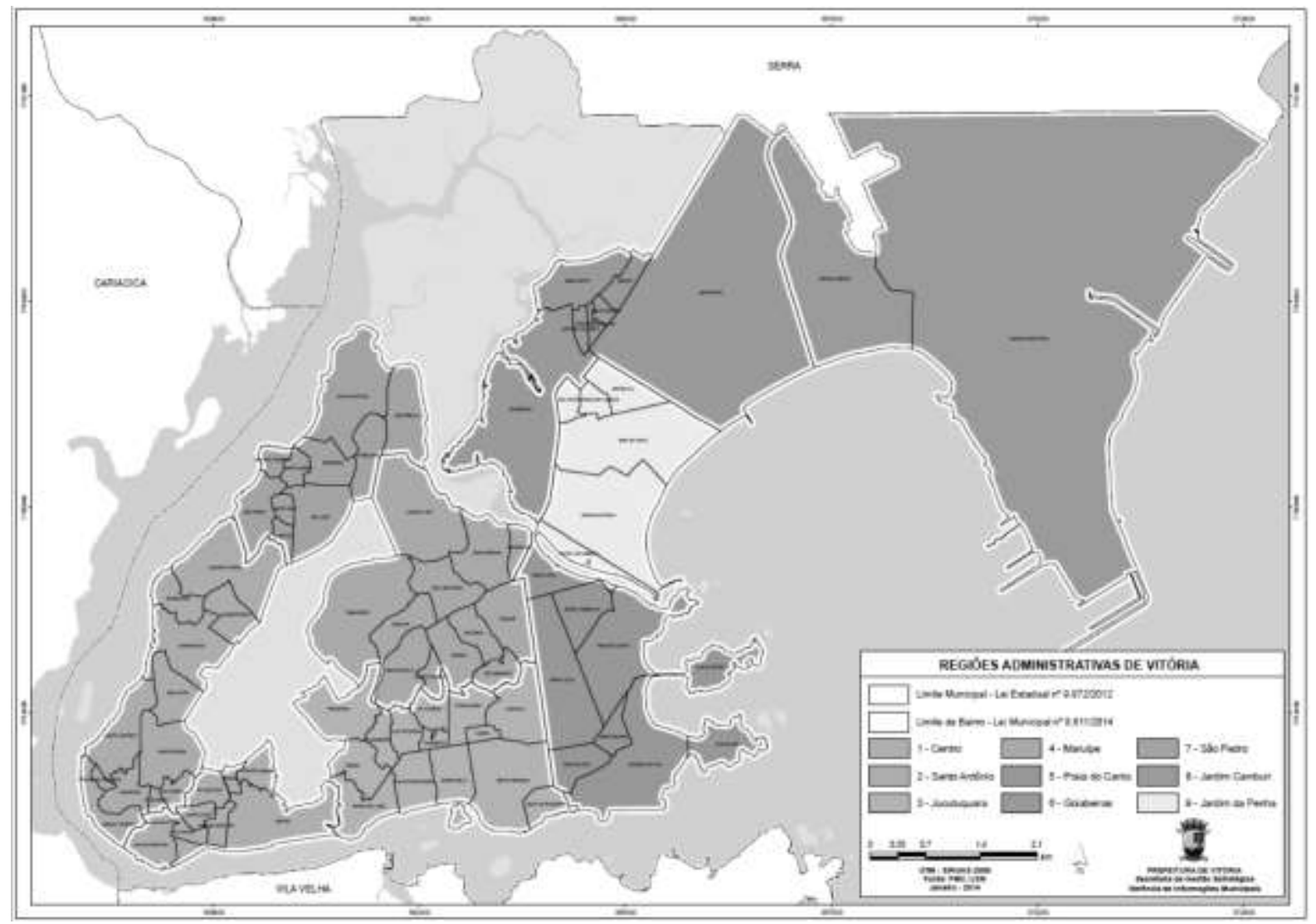

Analisando os dados apresentados, é possível perceber que a região I, que abrigava o centro da cidade tinha, na década de 1970, a primazia na distribuição dos estabelecimentos varejistas, com $59,1 \%$ dos estabelecimentos varejistas. Conforme os anos foram passando, apesar do crescimento do número de estabelecimentos em todas as regiões, em termos proporcionais o centro perdeu relevância, chegando a 30,3\% em 1999. Em relação aos registros de pessoas jurídicas na Prefeitura em 2012 , a proporção chegou a 17,7\%. Ao mesmo tempo, a região da Praia do Canto, que em 1970 apresentava apenas 8,8\% dos estabelecimentos varejistas, em 1999 abrigava 22,6\%, passando a 27,7\% de registros de pessoas jurídicas em 2012.

Outro destaque foi observado na região de Goiabeiras, que detinha $3,8 \%$ dos estabelecimentos, passando para $20,4 \%$ no período. As duas regiões, quando se observa o número de registros de pessoas jurídicas em 2012 detêm 53,7\% do total. A região de Jucutuquara também apresenta algum destaque, com números relevantes 
para todos os períodos. O quadro 3 apresenta uma representação coroplética da média e o desvio padrão da incidência de estabelecimentos varejistas em 1970 e 1990 e do registro de pessoas jurídicas na prefeitura em 2012.

Quadro 3 - Desvios-padrão em relação à média de Estabelecimentos varejistas em 1970 e 1990 e Pessoas jurídicas registradas na Prefeitura em 2012 nos bairros de Vitóriaiii

Quadro 3A - Estabelecimentos varejistas 1970

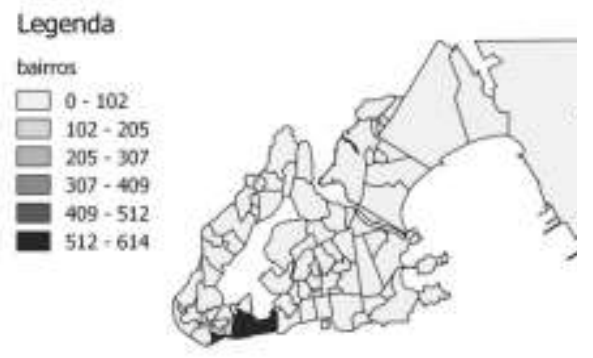

Quadro 3B - Estabelecimentos varejistas 1990
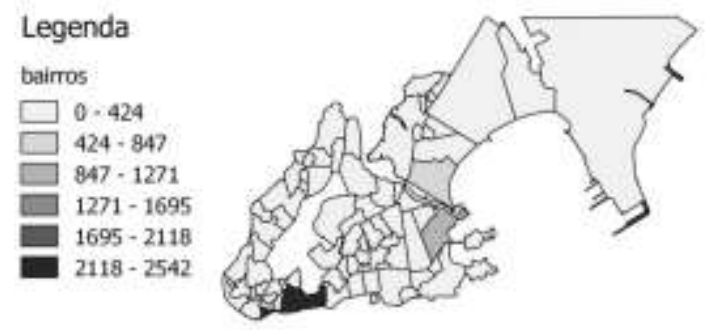

Quadro 3C - Pessoas jurídicas registrados na Prefeitura de Vitória em 2012

\section{Legenda}

bairros

$3-618$

$618-1233$

$1233-1848$

$1848-2463$

$2463-3078$

$3078-3693$

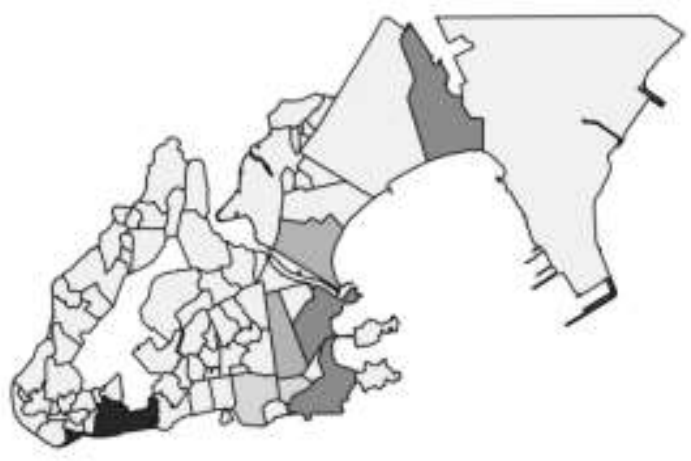

Fonte: Censo IBGE (2010) e Prefeitura Municipal de Vitória (2016)

Os mapas do quadro 3 mostram os dados escolhidos da tabela 1 de maneira espacializada. É possível observar que na década de 1970, os bairros mais importantes, em termos da incidência de estabelecimentos varejistas, eram o Centro, e em seu redor, a Vila Rubim, o Parque Moscoso e a llha do Príncipe, todos na Região I. A região III, que representava $12,9 \%$ dos estabelecimentos, apresentava três dos dez bairros com quantidade de estabelecimentos acima de um desvio padrão. 
No mapa de vinte anos depois, dos anos 1990, o Centro continuar a figurar na representação acima de três desvios padrão, junto com a Praia do Canto. A região, que ainda contava com destaques de Santa Lúcia, Santa Luíza e Praia do Suá, representava $18,4 \%$ do total de estabelecimentos. Além disso, Jardim da Penha, que apresentava mais que dois desvios padrão acima da média, já indicava a mudança da centralidade em direção a região do continente.

Quando se analisam os valores de registros de pessoas jurídicas na Prefeitura em 2012, percebe-se que há a consolidação de uma centralidade na região das praias em direção ao continente. Mais que isso, os bairros de Jardim Camburi e Jardim da Penha, atualmente os dois mais populosos da capital, com 39.087 e 30.522 residentes em domicílios, respectivamente passaram a também a figurar entre aqueles com número superior a três desvios padrão.

A outra informação a ser observada é que os bairros ao norte da ilha não figuram com nenhum bairro com número destacado de estabelecimentos varejistas. A contrário, o bairro da llha do Príncipe, que aparecia nos mapas da década de 1970 e $1990 \mathrm{com}$ valor acima de um desvio padrão, quando se analisam os dados de 2012, passa a apresentar valores medianos. Aparentemente o centro urbano passa a espalhar-se ao longo da região ao sul da ilha e em direção ao continente. A tabela 2 apresenta estatísticas descritivas da distribuição nos períodos.

Tabela 2 - Estatísticas descritivas dos estabelecimentos varejistas entre 1970 e 1999 e pessoas jurídicas registradas na Prefeitura em 2012

\begin{tabular}{lrrrrr}
\hline \multicolumn{1}{c}{ Indicador } & $\mathbf{1 9 7 0}$ & \multicolumn{1}{c}{$\mathbf{1 9 8 0}$} & \multicolumn{1}{c}{$\mathbf{1 9 9 0}$} & \multicolumn{1}{c}{$\mathbf{1 9 9 9}$} & \multicolumn{1}{c}{$\mathbf{2 0 1 2}$} \\
\hline \hline Média & 19,81 & 54,91 & 115,89 & 176,39 & 303,72 \\
Mediana & 3,00 & 9,00 & 23,00 & 38,50 & 132,00 \\
Desvio-padrão & 72,37 & 178,43 & 313,49 & 412,67 & 578,44 \\
Coeficiente de variação & 3,65 & 3,25 & 2,70 & 2,34 & 1,90 \\
Coeficiente de Gini & 0,859 & 0,814 & 0,784 & 0,758 & 0,668 \\
\hline
\end{tabular}

Fonte: Reis (2007) e Prefeitura Municipal de Vitória (2016).

Analisando os dados, observa-se que entre 1970 e 1999, o número médio de estabelecimentos varejistas por bairro ampliou-se 790,4\%. Ao mesmo tempo, o coeficiente de variação caiu de 3,65 para 2,34. Isso implica que, proporcionalmente, o desvio-padrão diminuiu em relação à media. O coeficiente de Gini também aponta uma 
desconcentração do número de estabelecimentos no período. Quanto ao número de pessoas jurídicas registradas na Prefeitura em 2012, os valores apontam para uma desconcentração ainda maior, uma vez que o coeficiente de variação aponta 1,90 e o indicador de Gini 0,668.

\section{ASPECTOS SOCIOECONÔMICOS DA CENTRALIDADE DE VITÓRIA}

O outro aspecto que pode ser analisado em relação à concentração dos centros urbanos diz respeito à renda. Corrêa, Pitaudi e Vasconcelos identificam que, ao se tratar de indivíduos, as noções ligadas à divisão do espaço dizem respeito à exclusão. Para eles, "Os excluídos seriam pessoas rejeitadas fisicamente (racismo), geograficamente (gueto) e materialmente (pobreza) [...]" (2013, p. 22). A ideia é que as populações excluídas formam aglomerados que podem ser no interior das regiões centrais, em áreas segregadas, ou afastadas do centro gerando áreas marginalizadas ou periféricas.

Milton Santos (2003) identifica que "Nos países subdesenvolvidos, o potencial de consumo individual varia muito, porque o nível de renda é função da posição do indivíduo no espaço. Esta localização determina, por sua vez, a capacidade individual de produzir e de consumir." (2003, p. 126). Ou seja, a localização é um elemento fundamental para o auferimento de renda para a população, de maneira que a questão econômica aparece como um dos elementos mais importantes para identificar a exclusão.

Apesar de apresentar-se em termos econômicos, a segmentação nos centros urbanos modernos não se limita a essas questões.

[...] outros espaços da vida social, especialmente os relativos ao consumo de bens e serviços, com destaque para os atinentes ao lazer, ela tem associação direta com a redefinição da centralidade, tanto na escala da cidade, como no plano interurbano, porque as possibilidades de mobilidade espacial e de comunicação são bastante diferentes, no caso brasileiro, segundo as condições socioeconômicas de diferentes segmentos sociais. Não por acaso, shopping centers, hipermercados, centros de eventos e negócios, grandes hotéis e outros espaços de oferta de bens e serviços de maior preço no mercado tên estratégias de localização espacial que se orientam por essas possibilidades e reforçam as distâncias sociais. (CORRÊA, PITAUDI e VASCONCELOS, 2013, p. 82) 
Por esse entendimento, as questões referentes à exclusão social podem ser observadas em relação à lógica econômica, mas com outros elementos que a configuram. Para tentar interpretar as questões relativas à exclusão pode-se comparar a distribuição da renda com a incidência dos equipamentos urbanos nos bairros. Segundo a NR 9284/86, equipamentos urbanos são "todos os bens públicos e privados, de utilidade pública, destinados à prestação de serviços necessários ao funcionamento da cidade, implantados mediante autorização do poder público, em espaços públicos e privados. (ASSOCIAÇÃO BRASILEIRA DE NORMAS TÉCNICAS, 1986, p. 1)". A tabela 3 mostra estatísticas descritivas de dados socioeconômicos e dos equipamentos urbanos $^{\text {iv }}$ em Vitória, segundo a prefeitura municipal.

Tabela 3 - Estatística descritiva dos dados socioeconômicos e dos equipamentos urbanos em Vitória

\begin{tabular}{clrrrrr}
\hline $\begin{array}{c}\text { Categoria do } \\
\text { indicador }\end{array}$ & \multicolumn{1}{c}{ Indicador } & \multicolumn{1}{c}{ Média } & Mediana & Desvio-padrão & $\begin{array}{c}\text { Coeficiente de } \\
\text { variacão }\end{array}$ & $\begin{array}{c}\text { Coeficiente de } \\
\text { Gini }\end{array}$ \\
\hline \hline \multirow{2}{*}{ Econômicos } & Renda per capita & $1.247,90$ & 736,38 & $1.373,20$ & 1,100 & 0,4715 \\
& Renda geral do bairro & $5.998 .800,00$ & $2.066 .200,00$ & $14.055 .000,00$ & 2,343 & 0,7136 \\
\cline { 2 - 7 } & População residente & $\mathbf{4 . 1 1 6 , 4 0}$ & $\mathbf{2 . 3 9 3 , 3 0}$ & $\mathbf{5 . 8 1 8 , 3 0}$ & $\mathbf{1 , 4 1 3}$ & $\mathbf{0 , 5 3 8 1}$ \\
\hline \multirow{2}{*}{ Assistência social } & 0,84 & - & 1,10 & 1,309 & 0,6454 \\
& Cultura e entretenimento & 0,60 & - & 2,08 & 3,474 & 0,8884 \\
& Educação & 5,46 & 3,00 & 8,72 & 1,596 & 0,6061 \\
& Esporte e lazer & 2,79 & 2,00 & 3,48 & 1,250 & 0,5745 \\
Equipamentonyyyyyyyyyyyyyy urbanos & Estabelecimentos comerciais & 5,83 & 1,00 & 16,43 & 2,821 & 0,8307 \\
& Hotel & 0,66 & - & 1,97 & 2,980 & 0,8948 \\
& Religioso & 3,85 & 2,00 & 4,78 & 1,241 & 0,5913 \\
& Saúde & 1,23 & 1,00 & 1,79 & 1,464 & 0,6729 \\
& Segurança urbana & 1,06 & - & 2,62 & 2,467 & 0,7839 \\
& Turismo trabalho e renda & 0,99 & - & 1,78 & 1,798 & 0,7150 \\
& Outros equipamentos & 3,39 & 2,00 & 5,06 & 1,493 & 0,6107 \\
\cline { 2 - 7 } & Total de equipamentos & $\mathbf{2 7 , 2 7}$ & $\mathbf{1 5 , 5 0}$ & $\mathbf{3 6 , 0 0}$ & $\mathbf{1 , 3 2 0}$ & $\mathbf{0 , 5 4 5 9}$ \\
\hline
\end{tabular}

Fonte: Censo IBGE (2010) e Prefeitura Municipal de Vitória (2016)

Em relação aos indicadores econômicos, é possível perceber que a distribuição da renda per capita é menos desigual que a da população, sobretudo no que se refere ao coeficiente de variação, 1,100 e 1,413, e ao indicador de gini, com valores de 0,4715 e 0,5381, respectivamente. Mesmo assim, quando se compara a renda geral do bairro, é possível perceber uma concentração bem maior que a observada para os outros indicadores, 2,343 no coeficiente de variação e 0,7136 do indicador de gini. Esse fenômeno pode ser explicado pela maior incidência de população nos bairros mais ricos, distribuindo o valor per capita. 
No que concerne aos equipamentos urbanos, observa-se que, no geral, a distribuição é aproximada em relação à população. Entretanto em segmentos específicos pode-se observar uma concentração mais elevada que o da população. Os cinco tipos de estabelecimentos com distribuição mais concentrada, a partir do indicador de gini, são: i) Hoteis 0,8948; ii) Cultura e entretenimento 0,8884; iii) Estabelecimentos comerciais 0,8307 ; iv) Segurança urbana 0,7839 ; e v) Trabalho, turismo e renda 0,7150. todos com concentração bem mais elevada que a da população. Entre os equipamentos cuja distribuição apresenta-se menos concentrada, estão: i) Esporte e lazer 0,5745; ii) Religioso 0,5913; iii) Educação 0,6061; iv) Assistência social 0,6454; e, v) Saúde 0,6729. Além disso, outros estabelecimentos apresentaram valor de 0,6107 para o índice. Pelas informações apuradas, é possível inferir que há uma concentração maior dos equipamentos elencados por Corrêa, Pitaudi e Vasconcelos (2013). Além disso, como a média dos equipamentos com indicador de gini menos elevado é maior, em termos médios, a distribuição de equipamentos parece como mais equânime.

Mesmo que seja possível identificar a concentração com estatísticas descritivas, para ser possível caracterizar o tipo de exclusão social, é necessário estabelecer critérios em termos geográficos. O quadro 4 apresenta a distribuição da média e desvios-padrão dados socioeconômicos e equipamentos urbanos pelos bairros de Vitória. 
Quadro 4 - Desvios-padrão em relação à média de população residente, renda per capita, estabelecimentos comerciais e demais equipamentos urbanos nos bairros de Vitória

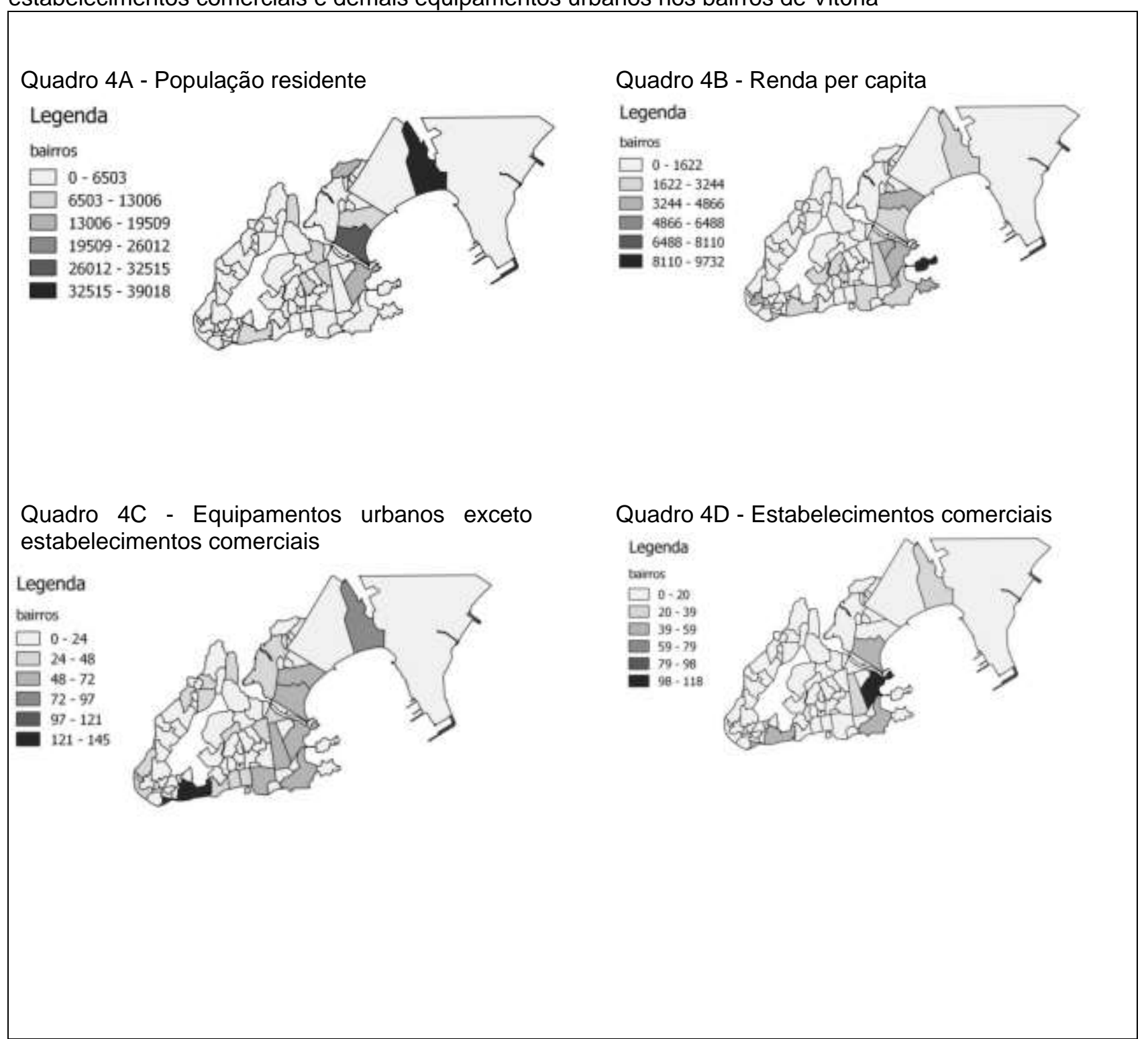

Fonte: Censo IBGE (2010) e Prefeitura Municipal de Vitória (2016)

Quanto à população residente, há apenas seis bairros cuja população encontrase acima de dois desvios-padrão e eles estão concentrados nas praias a sudoeste do maciço central, em direção ao continente. Os dois bairros com população acima de dois desvios padrão são Jardim Camburi e Jardim da Penha. Mesmo assim, diversos bairros ao norte da ilha contam com populações superiores a um desvio-padrão da média. Quando se compara a população residente com a renda per capita, observa-se inicialmente que, assim como podia ser previsto analisando as estatísticas descritivas, 
em alguns dos bairros mais ricos encontram-se as maiores populações. Mesmo assim, não há nenhuma incidência de regiões com renda per capita acima da média na parte norte da ilha.

Nesse sentido, é possível perceber algum grau de marginalização dessas populações, por estarem distantes dos bairros mais ricos. Outros estudos sobre a mobilidade permitiriam identificar como o acesso dessas populações aos bairros mais ricos se dá, autorizando inferências mais robustas. Observa-se ainda, alguns dos elementos que Corrêa descreve no modelo de Hoyt para descrição da cidade contemporânea, quando os bairros mais ricos são separados ficam afastados dos mais pobres através dos bairros de renda média.

No que se referem aos equipamentos urbanos, quando se excetua os estabelecimentos comerciais, é possível observá-los no norte da ilha. Sua incidência nos bairros coincide, ainda que com alguma divergência, com a de populações acima da média. Quanto ao Bairro Centro, apresenta um número maior de equipamentos urbanos, divergindo inclusive de sua população correspondente. Trata-se de uma evidência que aparece nos centros antigos das cidades subdesenvolvidas, conforme apresenta Corrêa (1989).

Em relação aos estabelecimentos comerciais, entretanto, com exceção do Centro, que possuiu uma grande incidência de estabelecimentos, é possível observa uma concentração evidente nos bairros com renda per capita mais elevada próximos e no continente. Nenhum bairro ao norte do maciço central apresenta um número de estabelecimentos comerciais acima de um desvio padrão em relação à média. Trata-se de uma evidência de exclusão, em termos econômicos, daqueles bairros, que não fica tão clara no que diz respeito aos demais equipamentos urbanos. Além disso, os bairros da Ilha de Frade e Ilha do Boi, que apresentam as maiores rendas per capita da capital, apresentam incidência média de estabelecimentos comerciais, identificando o fenômeno da autossegregação pela qual se excluem as populações ricas de algumas cidades brasileiras (cf. CORRÊA, PITAUDI e VASCONCELOS, 2013). Nesse caso, apesar de não haver uma fortificação ou incidência de fechamento em um condomínio, a característica desses bairros, duas ilhas, limitam a circulação. 


\section{CONSIDERAÇÕES FINAIS}

O trabalho teve por objetivo fazer um debate sobre centralidade no município de Vitória. A literatura sobre o tema indica os caminhos para fazer esse tipo de debate. Segundo Milton Santos (2008) as principais capitais brasileiras nascem e desenvolvemse a partir da ligação com o comércio internacional. Outras indicações sobre o tema apontam que esse processo vai desenvolvendo regiões de maneira desigual e, nos processos avançados, modificando as estruturas de centralidade, conforme aponta Corrêa (1989).

O tratamento dos dados permitiu identificar algumas dessas inferências no município de Vitória, com a análise que partiu dos anos 1970 até a década de 2010. As indicações apontaram para uma inicial concentração varejista no centro da cidade, com dispersão e modificação da centralidade ao longo do tempo. Em 2012, a concentração das inscrições de pessoas jurídicas na Prefeitura apresentou-se principalmente nos bairros da Praia do Canto, Santa Lúcia, Enseada do Suá, Jardim da Penha e Jardim Camburi. Ou seja, a centralidade econômica caminhou, ao longo do tempo, para as praias do sudeste do maciço central, em direção ao continente.

Outras evidências teóricas, conforme Corrêa, Pitaudi e Vasconcelos (2013) apontam para a configuração das formas espaciais e de exclusão dos indivíduos na cidade. Para essa avaliação observou-se os dados do Censo do IBGE (2010) e a listagem de equipamentos urbanos da Prefeitura Municipal de Vitória (2016). As evidências apontaram para um tipo de marginalização, no sentido da relação de centro e periferia, nos bairros ao norte da ilha. Outros estudos poderiam ser feitos para qualificar essa marginalização, identificando as questões do acesso dessas populações à região central. Mesmo assim, a existência do maciço central dividindo as regiões mais ricas das outras é um indício de dificuldade de acesso.

O estudo não permitiu fazer inferências consistentes em relação à marginalização em termos que não fossem econômicos. As indicações são de que a incidência geral de equipamentos urbanos tem alguma relação com a população residente nos bairros. Entretanto, no caso das estatísticas descritivas observou-se 
concentração acima da média em equipamentos de hotéis, cultura e entretenimento, trabalho turismo e renda e segurança urbana.

\section{REFERÊNCIAS}

ABNT. NR 9284/86 - Equipamento Urbano. 1986.

BUFFON, J. A. Esgotamento da fronteira, criso do café, novas fontes de dinamismo e os limites da agricultura familiar no Espírito Santo. In: BUFFON, J. A. O café e a urbanização no Espírito Santo: Aspectos econômicos e demográficos de uma agricultura familiar. Dissertação de mestrado apresentada ao Programa de Pósgraduação da Universidade Estadual de Campinas, Campinas, 1992.

CAMPOS JR, C. T. Novo Arrabalde. Vitória: PMV, Secretaria Municipal de Turismo, 1996.

CARLOS, R. M.; RICCI, F. Centralidade, segregação e estruturação do espaço interurbano: A transição da sociedade rural para a urbana em Taubaté. XVI Encontro Nacional ANPUR, Belo Horizonte, 18-22 Maio 2015.

CORRÊA, R. L. O espaço urbano. São Paulo: Editora Ática, 1989.

CORRÊA, R. L.; PINTAUDI, S. M.; VASCONCELOS, P. D. A. A cidade contemporânea: Segregação espacial. São Paulo: Editora Contexto, 2013.

GONRING, R. Redefinição funcional do centro de Vitória. Dissertação de mestrado apresentada ao Programa de Pós-Graduação em Geografia da UFES, Vitória, 2011.

HARVEY, D. A produção capitalista do espaço. São Paulo: Annablume, 2005.

IBGE. Censo 2010. Site do Instituto Brasileiro de Geografia e Estatística. 2016. Disponível em: < http://www.sidra.ibge.gov.br/cd/cd2010RgaAdAgsn.asp>. Acesso em: 03 de Maio de 2016.

MARTINELLI, M. Representações quantitativas - Manifestação em Área: Método coroplético. In: MARTINELLI, M. Mapas da geografia e cartografia temática. São Paulo: Contexto, 2009. p. 61-64.

PREFEITURA MUNICIPAL DE VITÓRIA (PMV). Vitória em dados. Site da Prefeitura Municipal de Vitória, 2016. Disponivel em: <http://legado.vitoria.es.gov.br/regionais/home.asp>. Acesso em: 31 maio 2016.

REIS, L. C. T. Descentralização e desdobramento do núcleo de negócios na cidade capitalista: Estudo comparativo entre Campo Grande e Praia do Canto, na 
Grande Vitória-ES. Rio de Janeiro: Tese apresentada ao Programa de Pós-Graduação em Geografia da UFRJ, Rio de Janeiro, 2007.

SANTOS, M. Uma revisão da teoria dos lugares centrais. In: SANTOS, M. Economia espacial: Críticas e alternativas. $2^{\underline{a}}$ edição. ed. São Paulo: Universidade de São Paulo, 2003. Cap. 4.

2008.

. O espaço dividido. São Paulo: Editora da Universidade de São Paulo,

THISSE, J. F. Geografia Econômica. In: CRUZ, B. D. O., et al. Economia regional e urbana: teorias e métodos com ênfase no Brasil. Brasília: Ipea, 2011.

Recebido em: novembro de 2017

Aceito em: dezembro de 2017 
Anexo I - Estabelecimentos varejistas em 1970, 1990, 1980 e 1999 e pessoas jurídicas registradas na prefeitura em 2012

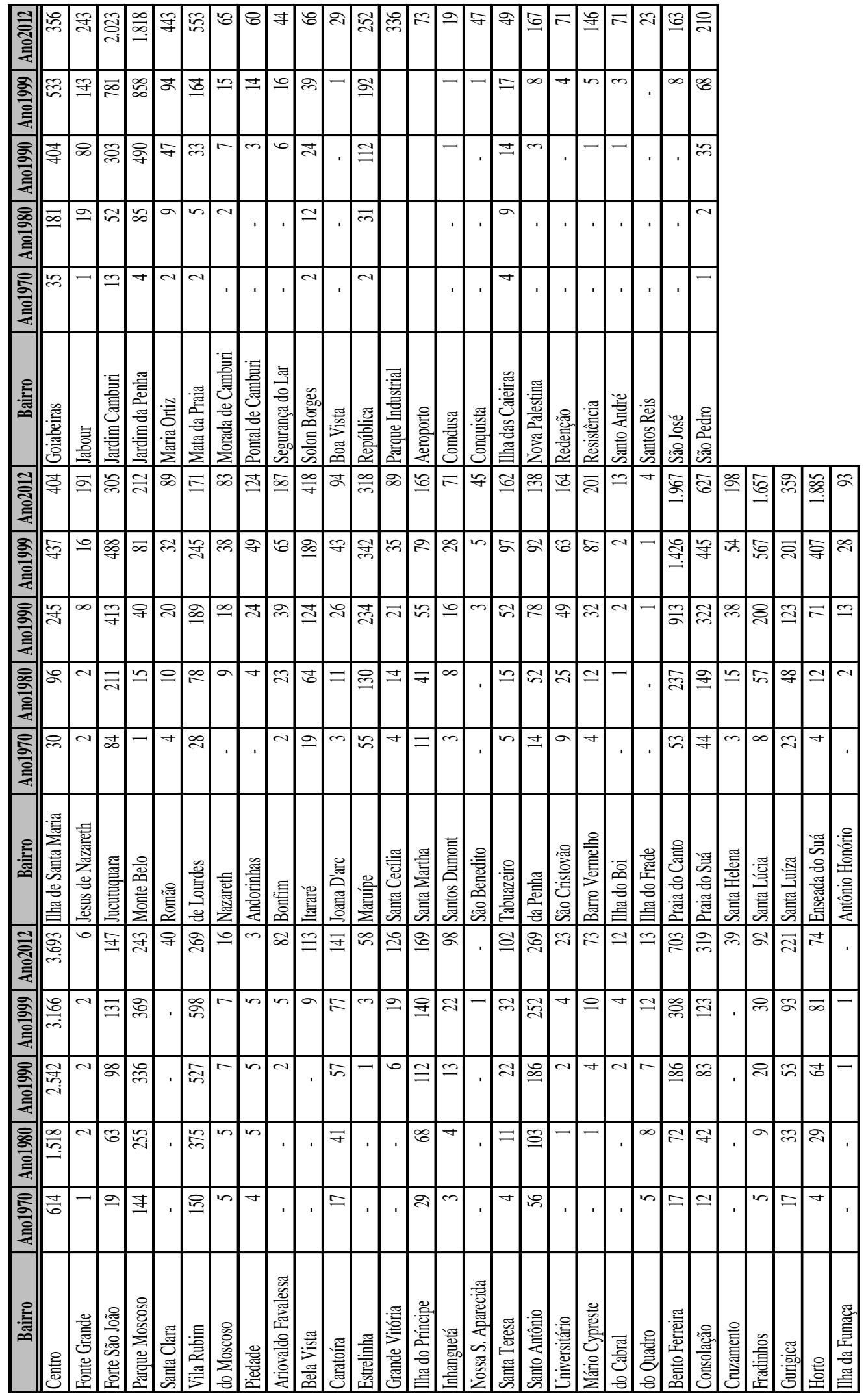




\section{Anexo II - Equipamentos urbanos e dados econômicos dos bairros de Vitória}

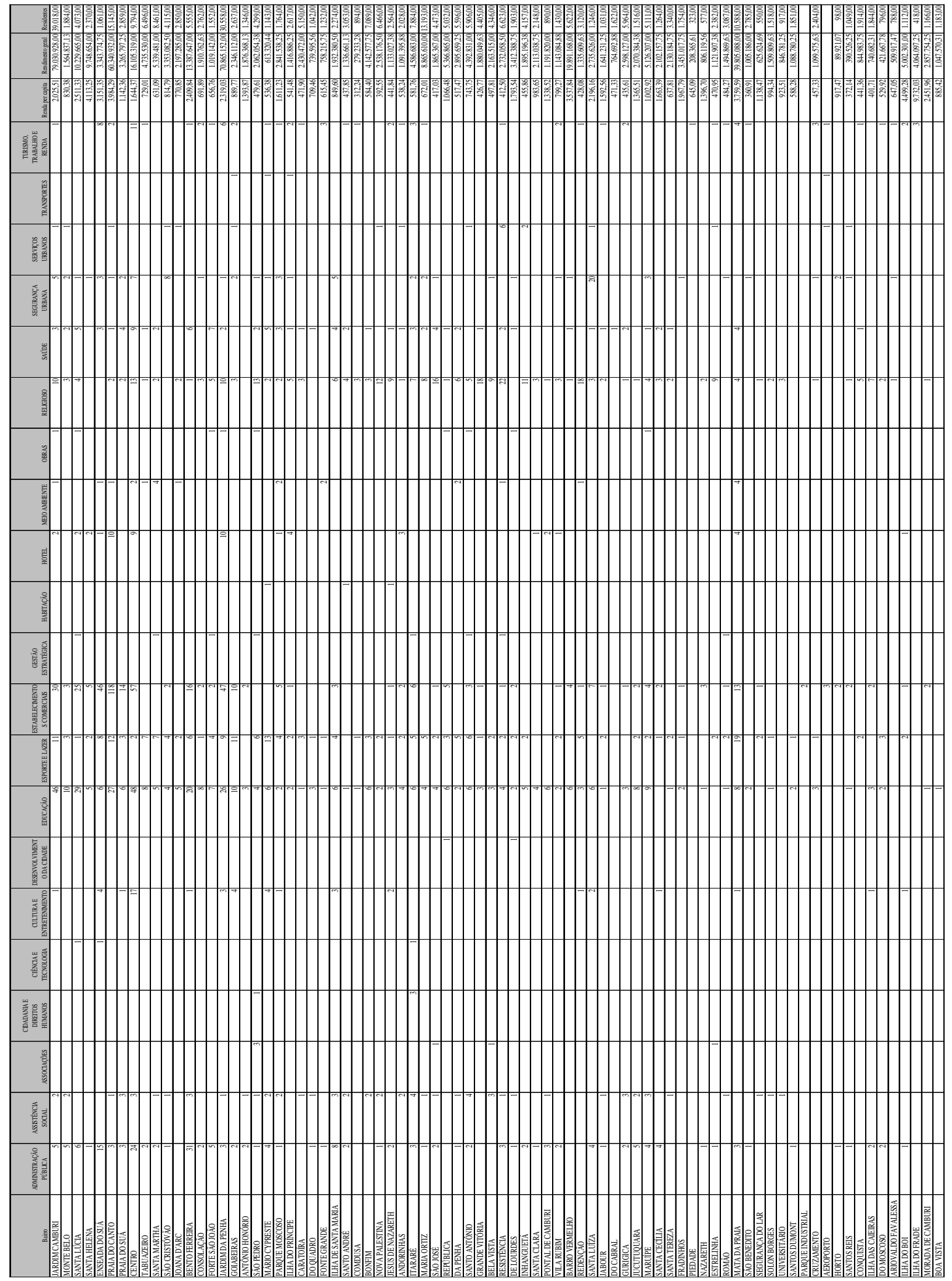




\begin{abstract}
${ }^{\text {i }}$ A base de comparação entre os dados absolutos de 1970 a 1999 é realizável, mas incompatível com os dados de 2012, pois a metodologia de levantamento é diferente. Entretanto, é factível que se suponha uma compatibilidade entre o número de estabelecimentos varejistas, em 1970 e 1999 e a proporção de pessoas jurídicas registradas na prefeitura em 2012. Assim, todas as comparações com os estabelecimentos varejistas são indicados em termos proporcionais. Além disso, para a análise, foi utilizado o conceito de Microempresa que exclui os microempreendedores individuais (MEI), uma vez que a legislação que estabelece essa categoria é de meados da década de 2000, não existindo para os períodos anteriores, para que essa proporção fosse mais adequada à realidade entre 1970 e 1999. A quantidade desses registros é significativa em relação ao montante de registros total, com $48,97 \%$. Ao todo, há, contando os MEls, 48.760 registros.
\end{abstract}

ii A esquematização de regiões utilizada foi aquela apresentada em Reis (2007), uma vez que contava com menos regiões que a atualmente utilizada pela Prefeitura. Atualmente são utilizadas mais duas: Região VIII - Jardim Camburi, apenas com o próprio bairro; e Região IX - Jardim da Penha, que além do próprio bairro, passou a abrigar Bairro República, Boa Vista e Morada de Camburi.

iii Segundo Martinelli, apesar de frequentemente ser utilizado para descrever valores absolutos, o método coroplético é mais adequado para estudos de valores relativos. Em sua definição, "Este método estabelece que a ordem crescente dos valores relativos agrupados em classes significativas seja transcrita por uma ordem visual também crescente" (2009:61). A estrutura apresentada compara o quantitativo do indicador do bairro para cada variável com a quantidade de desvios padrão da média. São elencados seis níveis de comparação. Entre os tons de azul, o mais escuro representa valores abaixo de três desvios-padrão, o tom intermediário representa valores entre dois e um desvio padrão e o tom mais claro de azul representa os valores entre um desvio padrão menores que a média e outro acima da média. Entre os tons vermelhos, o mais claro representa valores entre um e dois desvios padrão. A gradação em tom vermelho aumenta para valores entre dois e três desvios padrão e o tom mais escuro apresenta quantitativo acima de três desvios.

iv No que se refere aos estabelecimentos comerciais, somente estão na lista aqueles que são considerados na tabela de equipamentos urbanos da Prefeitura como tais. 